\title{
Synergetic Research on Cross-border E-commerce and Cross-border Logistics based on Ecosystem
}

\author{
Jing $\mathrm{HaO}^{1, \mathrm{a}}$ \\ ${ }^{1}$ Zhengzhou Institute of Technology, Zhengzhou, Henan, 450044
}

Keywords: Ecosystem, Cross-border E-commerce, Cross-border Logistics

\begin{abstract}
With the development of the economy, the annual increase in cross - border e-commerce business transactions increased year by year. But the objective environment of the impact of cross border e-commerce business enterprises or a lot of factors, such as the effectiveness of the logistics industry chain, the distribution cycle is long, the logistics records can not be effectively tracked, there are damage and loss of parcels, customs clearance obstacles, low efficiency , Logistics solutions and control means more backward and other factors are to a certain extent, can not make consumers get more quality services, thus hindering the development of cross - border e-commerce business. This paper analyzes the feasibility and necessity of the integration of cross - border e-commerce and logistics industry, analyzes the obstacle factors of the integration of the two, and finally puts forward the relevant research on the development of cross-border electric business and logistics industry chain Strategy.
\end{abstract}

\section{Introduction}

Cross - border e-commerce business from the narrow sense can be considered cross-border retail, in a broad sense that can be considered foreign trade. Cross - border e-commerce business refers to the existence of two different cross-border transactions in the main body through the e-commerce platform to make the two sides to reach a deal, and then by the buyer to pay, and then by the seller through the cross-border logistics to the goods delivered to the hands of buyers to complete the entire transaction Of a cross-border business activities. At present, China's cross - border e-commerce business is divided into two types, namely, B2B mode and B2C mode. B2B model, the enterprise using e-commerce platform to publish information, but the transaction, customs and other processes are completed online, and into the customs statistics, so B2B model is also within the scope of traditional trade. B2C model, the enterprise to sell personal consumer goods, transactions, payment and other processes are carried out in the e-commerce platform, and in the logistics side is the use of courier, air bag, mail, etc., courier companies, airlines, postal And so responsible for the declaration. As a result of the nature of cross-border electric business, it presents a global, multilateral, intangible, real-time, high frequency, anonymity, order duration is short, a wide range of goods, electronic information, innovation feature.

Logistics industry chain refers to the logistics and transportation related to the upstream and downstream, the surrounding or other industries, according to the logistics industry related to the logistics industry chain, including the following areas, namely: transport of goods transport vehicles to enhance the level of logistics information The information technology, logistics to improve the efficiency of the logistics technology to maintain the logistics center of the normal operation of the logistics equipment to provide storage of goods, such as logistics real estate. Based on the function of the logistics industry chain, it has the following characteristics in the actual operation: the logistics industry chain on a variety of service methods, namely, the transport industry, information industry, equipment manufacturing industry, logistics industry, Warehousing industry, loading and unloading industry and other aspects closely together; logistics industry chain and the service object integration, that is, through the supply chain management and home to form a close working relationship; logistics industry chain management closely related policies, government departments promulgated Laws and regulations for the development of the logistics industry provides an environment, and in the actual operation of the relevant laws and regulations for the development of the logistics industry pointed out the direction, and thus promote the development of the logistics 
industry.

\section{Cross - border E-commerce and Cross - border Logistics Model and Operation}

For the time being, our government has chosen moderately regulated principles to manage cross border e-commerce providers, in order to promote the positive development of cross - border e-commerce providers in our country; on the other hand, Model to complete the improvement of the multi-level supervision system, driving the whole business market to improve the vitality. Among them, the regulatory mechanism for the content is divided into two categories and one is online trade, that is, B2B model. In the international trade in such a logistics model has been developed more mature, with a complete set of operating rules. In the logistics mode, through the transport of goods to the hands of foreign consumers and then establish a transport system, storage systems and other facilities to complete a series of commodity trading activities. Under normal circumstances, enterprises involved in export trade will rely on electric goods, such as Alibaba, etc. to the goods of information, advertising and other content published and publicity, and trading activities are also completed online, is the traditional logistics model Online manifestation. Moreover, the B2C model, which is about to deal with small quantities of potential customers' volume orders, makes it a fragmented sales task, which makes it difficult for the traditional transport model to be valuable, and the shipping content is more sophisticated, specifically for the entire transportation industry Came the challenge.

In the past, the main body of the declaration is a postal enterprise, so it can not be included in the customs trade statistics. As the amount of cross-border trade continues to increase, the legal regulation of its level of continuous decline, there are some gray areas. Choose to establish a new regulatory model is to make the entire declaration activities more transparent, to achieve the whole process of traceability and control.

Power platform and logistics system is an inseparable as a whole, the business platform for business activities to carry out the model will directly affect the operation of the logistics system, which is beyond doubt. The development of cross-border logistics is still in the initial stage of development, so with a very obvious ambiguity, and such factors exist for the development of cross-border logistics to provide a variety of development space.

Through the analysis of the domestic electricity business platform to improve the construction of cross - border e-commerce providers, we need to pay attention to its transportation process optimization and production level. In the country, special step is with the courier company's warehouse with the integration of services, based on large data to achieve scientific warehouse storage and multi-warehouse close delivery. At present, some courier companies have been able to achieve $90 \%$ of the city's 24 -hour service, this logistics model is not only a good solution to the period of explosive crisis, but also help to enhance the large-scale promotional activities after the customer satisfaction with logistics services degree.

In the transaction mode, it is often necessary to choose the mode of cargo transhipment to meet the needs of consumers. The mode of transportation is small and involves a wide range, mainly through the relationship with consumers and merchants. The establishment of the transport channel and the improvement of the storage model to ensure that consumers can buy goods in a short period of time, from the business to reach the hands of consumers. Under normal circumstances, can be divided into two cases, one is by the outside of the electricity business platform to transport goods to the designated location, after the completion of the collection volume after the unified exit; both by purchasing the pre-purchase, by mail , The goods returned to the country by batch. In the meantime, the transshipment company is responsible for receipt inspection, customs clearance, transportation and transfer of domestic courier services. International logistics line, in the past usually refers to a specific region responsible for the international section of the transport agents and organizations. Now, cross - border e-commerce providers need to extend the green service to both ends: the import side, some have air and customs clearance of freight forwarding services or logistics enterprises, as overseas online shopping platform designated lines of transport distributors, direct online shopping platform to provide direct delivery to China After the import and export is 
responsible for the transfer to domestic distribution; export, for the domestic seller set cargo goods out of goods, through the international section of transport, to the end of the country to choose the distributor or postal, complete the buyer distribution. Green companies do not rely on resources, the essence of its operation is often integrated and resale, need to have a specific channel resources, foreign trade qualification, customs clearance and risk control and other capabilities.

Overseas business into China, the last one mile service competition. As the saying goes, the line half hundred and ninety, the last mile of the service often determines the consumer online shopping experience is good or bad. The United States a well-known business super into China, but it is neither in the physical store in China and no staff, how does it let the Chinese consumers perceive its brand through the service? With the best logistics to serve the end consumer, you can let Consumers through the last mile of service to perceive the brand's position, which is a brand of bit. Ultimately this American business super selection and cooperation with SF, which Taobao, Lynx some brands who adhere to choose SF is based on the same reason, because the quality of logistics services is the best endorsement of the brand. In the cross - border e-commerce business B2C exports, logistics quality, large transport and customs clearance and other factors often affect the seller's credit rating, overseas warehousing can be used as a supplementary program. Through the construction of overseas warehouses system and operating platform, one for the domestic cross-border electrician export sellers to provide more efficient logistics channel; the second is for cross-border imports to do outside the packaging and transport, to provide end-to-end service.

\section{Promote Cross - border E-commerce and Logistics Industry Chain Integration Development Strategy}

In recent years, government departments continue to improve the payment, settlement, logistics, taxation, information management, customs inspection and other relevant policies, but so far these policies for cross - border e-commerce and logistics industry chain integration development, there are still some Sound. Such as the tax set is not enough to keep up with the times, information management, information sharing within the scope of the content included.

The development of Cross - border E-commerce and logistics industry chain integration policy. And "cross - border e-commerce and logistics industry supply chain integration development" of the relevant policies are still scarce. As a result of cross-border electric business enterprises and logistics enterprises have their own conflicts of interest, resulting in a lack of trust between the two mechanisms, there are working processes difficult to reconcile the contradictions and so on. This requires the state to enact relevant policies, such as incentive policies, loan preferential policies, tax incentives, information sharing regulations, so as to promote cross - border e-commerce and logistics industry to achieve integration development.

In order to meet the increasing demand for cross - border e-commerce providers, you can enhance the level of logistics enterprise infrastructure, overseas Jiancang and other aspects to implement. Which need to consume a lot of manpower, material and financial resources, and for international buyers, but also need to consider the cultural environment and the basic national conditions, but also need to achieve integration with the international community, which is the majority of logistics enterprises can not be completed. To enhance the level of infrastructure and management of logistics enterprises can not be achieved overnight, but in the long run its sound development of the entire logistics industry chain is of great significance; Moreover, the strength of existing logistics enterprises, but also to promote cross - border e-commerce providers And the integration of logistics industry chain development of the key factors. So as to enhance the level of logistics enterprise infrastructure, you need to improve from the logistics industry chain on the following aspects: First, freight transport, large tonnage of trucks, trucks and trains, ships, aircraft, etc .; Second, the logistics information technology, Such as WMS, TMS, OMS and other logistics systems; Third, the logistics efficiency improvement technology, such as information transmission belt, lifting equipment, scanning equipment, disinfection equipment, monitoring devices, GPS positioning devices, automated warehouses, etc .; Fourth, Such as tractors, forklifts, shelves, lifts, etc .; fifth, to provide storage of goods logistics real estate, such as freight markets, logistics parks 
and so on. From the entire logistics industry chain to enhance the logistics enterprise infrastructure level, so as to meet the needs of cross - border e-commerce providers, which is conducive to the rapid realization of cross - border e-commerce and logistics industry integration development.

Cross - border e-commerce and logistics industry belong to the same business, there is a conflict of interest is inevitable, so the conflict of interest can also be seen as the fundamental between the two do not trust, so the establishment of appropriate distribution of benefits becomes very important. Cross - border e-commerce and the distribution of the interests of the logistics industry involves two aspects, one is beneficial to both sides of the cooperation program and benefit distribution program, and the other is the way of capital flows. In these two areas, the cooperation program and the benefit distribution scheme can be intervened by the government departments to ensure that the final program is satisfactory to both parties; and the flow of funds and distribution can be financed by means of a third party payment platform But also to the goods from the order to the hands of consumers into the process of giving the right to monitor the two sides to ensure that the entire transaction process and the logistics process transparent and open, to reduce mutual suspicion between each other and enhance the trust of both sides. At the same time as a government department, at this time for the realization of the integration of enterprises to provide some preferential policies and mutual cooperation provisions, so as to ensure the close relationship between the two sides. In this way, it will make cross - border e-commerce and logistics industry chain to establish a good relationship between the trust mechanism, so as to truly achieve integration, and jointly contribute to the development of the Internet economy.

\section{Conclusion}

To promote the integration of cross - border e-commerce and logistics industry chain development, cross - border e-commerce business logistics to achieve seamless docking, so that cross - border e-commerce business enterprises to provide consumers with more quality services to promote China's e-commerce enterprises and logistics industry Comprehensive development is the current solution to the difficulties faced by cross - border e-commerce business enterprises and promote the development of the logistics industry chain, an important measure.

\section{References}

[1] Cao Qian. Xuzhou City, the development trend of modern logistics industry [J]. Modern economic information, 2016 (11)

[2] Wang Jinghong. Zunhua City, the development of modern logistics industry and measures [J]. Statistics and Management., 2015 (06)

[3] Chaihai Rui. Zhengzhou modern logistics industry development constraints and ideas to explore [J]. Modern business, 2015 (30)

[4] Zhang Yuxi. Nanyang City, the development of modern logistics industry analysis [J]. China Management Information, 2016 (19)

[5] Chaihai Rui. Policy support to promote the development of modern logistics industry in Zhengzhou [J]. Modern business, 2015 (32) 